\title{
Editorial
}

\section{Sensors Best Paper Award 2012}

\section{Ophelia Han}

MDPI AG, Postfach, CH-4005 Basel, Switzerland and MDPI Branch Office, Beijing 101101, China; E-Mail: ophelia.han@mdpi.com; Tel.: +86-10-5901-1009; Fax: +86-10-5901-1089

Received: 20 January 2012 / Accepted: 23 January 2012 / Published: 23 January 2012

Since 2011, Sensors has been instituting an annual award to recognize outstanding papers that are related to sensing technologies and applications and meet the aims, scope and high standards of this journal [1]. To improve the timeliness of the award, we have decided that starting from next year, only papers published in the preceding three years will be eligible for the competition.

In this year, nominations were made by the Section Editor-in-Chiefs of Sensors from a pool of all papers published in Sensors from 2006 to 2008, in which reviews and articles were considered separately. We gladly announce that the following five papers have won the Sensors Best Paper Award in 2012.

\section{Article Award:}

$1^{\text {st }}$ Prize

Hongying Zhu, Jonathan D. Suter, Ian M. White and Xudong Fan

Aptamer Based Microsphere Biosensor for Thrombin Detection

Sensors 2006, 6(8), 785-795; doi:10.3390/s6080785

Available online: http:/www.mdpi.com/1424-8220/6/8/785/

$2^{\text {nd }}$ Prize

Veronika Supalkova, Dalibor Huska, Vaclav Diopan, Pavel Hanustiak, Ondrej Zitka, Karel Stejskal, Jiri Baloun, Jiri Pikula, Ladislav Havel, Josef Zehnalek, Vojtech Adam, Libuse Trnkova, Miroslava Beklova and Rene Kizek

Electroanalysis of Plant Thiols

Sensors 2007, 7(6), 932-959; doi:10.3390/s7060932

Available online: http://www.mdpi.com/1424-8220/7/6/932/ 
$3^{\text {rd }}$ Prize

\section{Cédric Cochrane, Vladan Koncar, Maryline Lewandowski and Claude Dufour}

Design and Development of a Flexible Strain Sensor for Textile Structures Based on a Conductive Polymer Composite

Sensors 2007, 7(4), 473-492; doi:10.3390/s7040473

Available online: http://www.mdpi.com/1424-8220/7/4/473/

\section{Review Award:}

$1^{\text {st }}$ Prize

Dorothee Grieshaber, Robert MacKenzie, Janos Vörös and Erik Reimhult

Electrochemical Biosensors - Sensor Principles and Architectures

Sensors 2008, 8(3), 1400-1458; doi:10.3390/s8031400

Available online: http://www.mdpi.com/1424-8220/8/3/1400/

$2^{\text {nd }}$ Prize

\section{Hua Bai and Gaoquan Shi}

Gas Sensors Based on Conducting Polymers

Sensors 2007, 7(3), 267-307; doi:10.3390/s7030267

Available online: http://www.mdpi.com/1424-8220/7/3/267/

The prize awarding committee merits the article "Aptamer Based Microsphere Biosensor for Thrombin Detection" as "a well-written paper reporting very interesting scientific work, which is the type of paper we want to encourage submission of at Sensors", which reported "an interesting detection principle nicely coupled to the use of aptamers, a relative new type of biological reagent". The article "Electroanalysis of Plant Thiols" reported “... a nice, important application of an electrochemical technique...".

These five exceptional papers are valuable contributions to Sensors and the sensing field. On behalf of the Prize Awarding Committee and the Editorial Board of Sensors, we would like to congratulate these five teams for their excellent work. In recognition for their accomplishment, Drs. Xudong Fan, Rene Kizek and Vladan Koncar will receive a prize of $1000 \mathrm{CHF}, 800 \mathrm{CHF}$, and $500 \mathrm{CHF}$, and Drs. Erik Reimhult and Gaoquan Shi will receive a prize of $800 \mathrm{CHF}$ and $500 \mathrm{CHF}$, respectively, and the privilege to publish an additional paper free of charge in open access format in Sensors, after normal peer-review.

\section{Prize Awarding Committee}

Editor-in-Chief, Section 'Physical Sensors'

\section{Prof. Dr. Craig A. Grimes}

State Key Laboratory of Materials-Oriented Chemical Engineering, Department of Chemical Engineering, Nanjing University of Technology, Nanjing, China

E-Mail: craig.grimes40@gmail.com 
Editor-in-Chief, Section 'Remote Sensors'

\section{Dr. Assefa M. Melesse}

Department of Environmental Studies, ECS 339, Florida International University, 11200 SW 8th Street, Miami, FL 33199, USA

Tel. +1-305-348-6518; Fax: +1-305-348-6137

Website: http://www.fiu.edu/ melessea/

E-Mail: assefa.melesse@fiu.edu

Editor-in-Chief, Section 'Chemical Sensors'

\section{Prof. Dr. W. Rudolf Seitz}

Analytical Chemistry, Department of Chemistry, University of New Hampshire, Durham,

NH 03824-3598, USA

Tel. +1-603-862-2408; Fax: +1-603-862-4278

Website: http://www.unh.edu/chemistry/faculty/seitz_w.html

E-Mail: wrs@cisunix.unh.edu

Editor-in-Chief, Section 'Biosensors'

\section{Dr. Alexander Star}

Department of Chemistry, University of Pittsburgh, 219 Parkman Avenue, Pittsburgh, PA 15260, USA

Tel. +1-412-624-6493; Fax: +1-412-624-4027

Website: http://www.pitt.edu/ astar/

E-Mail: astar@pitt.edu

Editor-in-Chief, Section 'Sensor Networks'

\section{Dr. Tim Wark}

CSIRO ICT Centre, 1 Technology Ct, QCAT, Pullenvale, QLD 4069, Australia

Tel. +61-3327-4042; Fax: +61-3327-4455

Website: http://www.ict.csiro.au/staff/tim.wark/

E-Mail: tim.wark@csiro.au

\section{Managing Editor}

\section{Dr. Ophelia Han}

MDPI Beijing Office, Liyuanbeijie Road 186, Suite 307, Liyuan Town, Tongzhou District, Beijing 101101, China

E-Mail: ophelia.han@mdpi.com

\section{Reference}

1. Han, O. Sensors Best Paper Award 2011. Sensors 2011, 11, 1243-1245.

(C) 2012 by the authors; licensee MDPI, Basel, Switzerland. This article is an open access article distributed under the terms and conditions of the Creative Commons Attribution license (http://creativecommons.org/licenses/by/3.0/). 